\title{
INTELLECTUAL DISABILITY (MENTAL RETARDATION) - REVIEW OF LITERATURE AND SOME COMPLEMENTARY APPROACHES OF MANAGEMENT
}

\author{
Kasinadar Kanesalingavelan1, Sivam Sabhesan², Savitha $K^{3}$ \\ ${ }^{1}$ Associate Professor, Department of Psychiatry, Sree Mookambika Medical College, Kulasekaram. \\ 2 Professor (Retd.), Department of Psychiatry, Madurai Medical College, Madurai. \\ ${ }^{3}$ Intern, Christian Medical College, Vellore.
}

\section{ABSTRACT}

\section{BACKGROUND}

An individual with Mental Retardation (MR) has sub-normal intelligence and does not possess adequate skills to cope with the environment. ${ }^{[1]}$ About $3 \%$ of the population has an IQ below 70. It is not a single, specific disorder or a unitary concept. There are many causes and even after extensive investigations the exact cause remains unknown in up to $40 \%$ of cases. ${ }^{[2]}$ Development is a multidimensional process and Intellectual Disability (ID) is a symptom found in many disorders of known and unknown origins in the developmental period. Since it is a multifaceted disorder and as there is no definite cure, prevention and appropriate care by a multidisciplinary team is the norm. ${ }^{[3,4,5,6]}$ But there should not be any nihilistic attitude or 'nothing can be done' or 'no medical treatment possible' approach, which will be counterproductive to the affected and the caregivers for proper management. Early identification and diagnosis, proper guidance, care rather than cure, communicating the limitations of treatment and emphasis on possible rehabilitation methods, coordination among the various healthcare providers were identified as better remedial measures. $[4,5,6,7]$ Parents owing to anxiety, ignorance, illiteracy and lack of effective guidance used to take their children for various alternate and unproved management approaches.[8]

\section{KEYWORDS}

Intellectual Disability, Mental Retardation, Treatment Approaches, Team Work.

HOW TO CITE THIS ARTICLE: Kanesalingavelan K, Sabhesan S, Savitha K. Intellectual disability (mental retardation) - Review of literature and some complementary approaches of management. J. Evolution Med. Dent. Sci. 2017;6(5):435-441, DOI: 10.14260/Jemds/2017/96

\section{BACKGROUND}

Intellectual disability is a disorder with onset during the developmental period that includes both intellectual and adaptive functioning deficits in conceptual, social and practical domains. Developmental slowness may appear in all areas of functioning, but it is primarily evident in cognition and intellectual functioning. ${ }^{[9]}$

The diagnostic term 'intellectual disability' is the equivalent term for the ICD-11 diagnosis of 'intellectual disability disorder.' Moreover, the term replaces the older familiar term mental retardation (Public Law United States 111-256, Rosa's Law).[10]

Other related terms include intellectual impairment, mental deficiency, mental subnormality, feeblemindedness, hypophrenia, oligophrenia, oligergasia, etc.[11] It is variably described as a symptom, syndrome and a disorder referring to a behavioural syndrome, not constituting to a homogenous group. $[5,9,11]$ It does not have a single cause, mechanism, course or prognosis. The term 'mental retardation' was used by the American Association of Mental Retardation (AAMR) for the first time in 1961.[12] It is not a unique nosological entity, but refers to a level of intellectual and adaptive functioning below a cut-off point that is not even natural but is arbitrarily chosen in relation to the average level of functioning of the population at large.[6,11]

\section{Financial or Other, Competing Interest: None}

Submission 07-12-2016, Peer Review 29-12-2016,

Acceptance 09-01-2017, Published 16-01-2017.

Corresponding Author:

Dr. Kasinadar Kanesalingavelan,

\#3, Sonaiyar Koil Street,

Narimedu, Madurai-625002, Tamilnadu.

E-mail: kanesandr@gmail.com

DOI: $10.14260 /$ jemds/2017/96

\section{(c) (i) $(9)$}

Intellectual disability is described under neurodevelopmental disorders and the following 3 criteria must be met (DSM-5).[10]

1. Deficits in intellectual functions such as reasoning, problem solving, planning, abstract thinking, judgement, academic learning and learning from experience, confirmed by both clinical assessment and individualised and standardised intelligence testing.

2. Deficits in adaptive functioning that result in failure to meet developmental and socio-cultural standards for personal independence and social responsibility. The adaptive deficits limit communication, social participation, independent living, etc.

3. Onset of intellectual and adaptive deficits during the developmental period.

\section{Levels of Intellectual Disability}

As noted by Esquiral in 1845, ID is not a disease in and of itself, but the developmental consequence of some pathogenic process.[2] John Locke in 1690, differentiated mental illness from mental retardation. ${ }^{[2,5]}$ In 1905, Alfred Binet and Theodore Simon in France classified children with MR into Idiots, Imbeciles and Morons according to the number of test tasks completed. Lewis Terman's revision of Stanford-Binet Intelligence Scale introduced the concept of IQ and classified MR according to its scores in 1916.[5,11,13] The American Association on Mental Retardation (AAMR) definition in 1910 included the classifications of idiots (Mental age 2 years or younger), imbeciles (Mental age 2 - 7 years) and morons (Mental age 7 - 12 years).[2,5,11]

In AAMR (1959), the sub-average intellectual functioning was meant to be one standard deviation (IQ approximately 85 ) and the developmental period was 16 years and 5 degrees of severity of MR (Borderline, mild, moderate, severe and profound) was described.[5,9] In 1973, the definition was 
changed to two standard deviations (IQ approximately 70), thus eliminating the category of borderline $\mathrm{MR}$ and the developmental period was shifted to 18 years or younger resulting in less number of intellectual disability. AAIDD's (American Association on Intellectual and Developmental Disabilities) 1992 definition eliminated traditional nosology based on level of cognitive impairment (mild-to-profound) and instead sub-classifies by the required intensity and pattern of support systems' into 4 levels (intermittent, limited, extensive and pervasive).[9]

In 1967, Zigler proposed 2 groups of persons with ID, the mild and severe.[14] The differentiation of mild ID (IQ 50 - 69) and marked or severe ID (IQ under 50) consisting moderate, severe and profound forms of ID though artificial are there in the past published studies.[2,5,14] This IQ cut-off of around 50 is used to distinguish two sorts of ID, organic and normal variant (Sometimes described as 'sub cultural').[5] Marked ID is more often associated with neurological disorder and less often associated with social disadvantage in contrast to the more common mild ID. Only mild ID is associated with a below-average IQ in relatives.[2,5,9] This two-population conceptual model cannot be taken too literally, as they may co-exist with additive or synergistic effects. ${ }^{[2]}$ Severe MR has no socioeconomic, racial or geographic predilection. $[1,2,5,9,11]$

MR is usually subdivided into: 1 . Mild (IQ 50 - 55 to 70 75 ) - the educable retardates, 2. Moderate (IQ 35 - 40 to 50 55 ) - the trainable retardates, 3. Severe (IQ 20 - 25 to 35 - 40) and 4. Profound (IQ below 20 or 25).[5,9.11] These 4 levels have long been used, but they have come under criticism because of their focus on deficits instead of the strengths and competencies.[2,5]

In ICD-11 the severity levels are Mild, Moderate, Severe and Profound IDD, in addition to the provisional categories of other and unspecified IDD.

DSM-5 classification includes Mild, Moderate, Severe, Profound, Global developmental delay and Unspecified ID. The term 'Global Developmental Delay' is reserved for individuals under the age of 5 years when the clinical severity level cannot be reliably assessed during early childhood (DSM-5).[10]

\section{Epidemiology}

There are variations in the estimates of prevalence across countries and regions due to various methodological differences and how ID is defined over a period of time, the age range, time and methods of population ascertainment. $[2,13,15]$ Reported rate in childhood population varies between 9-14/1000 and 3-8/1000 in adulthood in developed countries and higher in developing countries.[2]

Intelligence Quotient (IQ) is a continuous measure, so when basing a definition of ID upon it the threshold is arbitrary and change in its threshold changes the prevalence (AAMR changed IQ to 84 to 70 in 1973 and then 70 - 75 in 1992).[5] If IQ is normally distributed in the population with a mean of 100 and standard deviation of 15 , then about $2 \%$ of the population will have an IQ less than 70.[2,5] According to Ferguson Smith and Connors, 1\% of the new-borns are affected with moderate-to-severe MR but the percentage falls subsequently due to deaths in infancy. When age is considered highest, prevalence is in the school-age group.[2,5,11] Given a Gaussian or bell-curve distribution of intelligence, $2.28 \%$ of individuals should fall 2 or more standard deviations below the general population average IQ of $100 .{ }^{[5]}$

There is difference of opinion regarding the prevalence of ID, whether it is $1 \%$ or $3 \%$ and this debate is based on [5] - 1 . IQ as the only criteria for diagnosing ID - Given the Gaussian distribution of IQ as many people has IQ between 70 and 74 as have IQ between $0-69$. So if the IQ cut-off is 75 , then the percentage increases. If there is less correlation between IQ and adaptive behaviour, then there is corresponding change in prevalence. 2. IQ remaining constant - The 3\% prevalence rate also assumes that an individual's IQ is perfectly constant and stable over time, but in reality, different aetiological groups may have different patterns and levels of IQ and there may be changes from infancy to childhood and later into adulthood. There may be decline in IQ over time (Down's syndrome, Fragile X syndrome). Children with cerebral palsy in contrast show remarkably same IQ over time.[2] 3. Identification rates are equal across a range of variables nearly every study finds that prevalence rates are low from birth to $5-6$ years, increasing rapidly in school years and then decrease after adolescent years. There is regional variation depending on level of education, the median household income, percentage of births to teen mothers. ${ }^{[5,16]}$ 4. Equal mortality rates - this assumption is obviously incorrect, particularly in the severe and profound levels of retardation.

By including other criteria such as deficits in adaptive behaviour or defining less severe ID as learning disabilities or accounting for variable rates of case identification and mortality across different age-groups, the estimates were reduced to $1 \% .^{[5]}$ The prevalence is higher among males than females, particularly in less than 15 years children.[2,5] In mildly retarded, males have about 1.5 -fold greater prevalence.[1,2,5,12] Gender differences are not evident among adults.[15,17] Prevalence also varies with time due to various preventive measures undertaken, Genetics Research Development and Social Development. ${ }^{[2]}$

Mild intellectual disability is the largest ID, possibly as much as $85 \%$, moderate ID $10 \%$, severe ID $3 \%-4 \%$ and profound ID around $1 \%$ - $2 \%$ of the population of people with ID.[5]

The most common causes of ID include Down syndrome, Fragile X syndrome and foetal alcohol syndrome.[2,3,11] Fragile $X$ syndrome is the most common inherited cause of MR and Fragile $\mathrm{X}$ mutation is the single most common monogenic cause of autism. ${ }^{[2,3]}$ Down syndrome is the most common chromosomal abnormality and the most frequently occurring disorder of MR, but it is not the most common inherited cause for ID because most of them are not transmitted from generation to generation. ${ }^{[3]}$

A meta-analysis of 31 psychiatric epidemiological studies done in India yielded an estimated prevalence rate of 0.4 (Das et al)[18] to 25.3 (Sethi et al 1972) ${ }^{[18]}$ per 1000 population with a decreasing trend of prevalence over the last 4 decades from 1964 to 2000 covering 8 states of the country.[18] In India on an average 21580 babies are being born per year with Down syndrome ${ }^{[19]}$ and 0 - 19 years of age group constitute $45 \%$ of the population of India, ${ }^{[20]}$ showing the magnitude of the problem the world faces.

\section{Aetiology}

Intellectual disability is not a disease or illness in itself,[21] but instead constitutes a heterogeneous group: genetic, 
metabolic, changes that follow trauma to the CNS at birth or later during the developmental period. Because of this heterogeneity, each one must be considered independently according to whether an associated syndrome (e.g. Down syndrome) or an associated aetiology (e.g. head trauma) is present. Consequently, there is no single cause, mechanism, clinical course or prognosis for ID.[11] Thinking is not characteristically disordered and perception is not distorted unless a concurrent mental disorder exists. Iodine deficiency is the most common preventable cause of ID worldwide and is more common in some regions of Asia and Africa.[22]

Disruption of neurogenesis, neuronal migration, cellular differentiation, intercellular communication, cytoskeleton organisation, synaptic vesicle transport and other cellular functions are common pathological changes and the most common being dendritic abnormalities, which may range from generalised dysgenesis to highly syndrome specific changes.[23] The cortex undergoes complicated developmental changes like layering, migrating, proliferating, interconnecting and myelination which goes on up to 2 years approximately.[2]

Multiple Congenital Anomalies (MCA) are defined as presence of 2 or more anomalies that usually are located in 2 or more different embryologic areas and are seen in about $3 \%$ of newborns.[22] Up to $40 \%$ of persons with MR of unknown cause have 3 or more major or minor anomalies. Generally, the presence of MCA indicates a significant probability that a syndrome exists and the unique combination of anomalies most often comprises a specific aetiology.[22] Minor anomalies identification is more useful, because they are more frequent and contribute substantially to the syndrome's pattern. An anomaly is a primary defect in which there is a basic alteration of structure, usually before the tenth foetal week. Major anomalies result from an intrinsic error in organogenesis (e.g. cleft lip). Minor anomalies (e.g. epicanthic fold) do not cause functional problems, but they are signs of disturbance in organogenesis.[22] The frequency of a feature in a specific syndrome is very important. For example in Down's, hypotonia has $100 \%$ frequency, making it more important than all other features, which have a $25 \%$ - 50\% frequency.[22] Never make a clinical judgment of a measurable parameter without measuring it.[22]

In about $40 \%$ of cases, no cause can be found.[2,5] About $5 \%$ of children have metabolic cause. [2] Obstetric factors contribute about $3 \%$ of cases and about $4 \%$ are due to environmental insults, which occur postnatally. Genetic factors play an important role in the aetiology of 30\% - 50\% of cases of ID.[13] If timing is used as classifying causes, then prenatal factors cause about $50 \%-70 \%$, perinatal around $3 \%$ - 20\%, postnatal around 5\% - 10\% and later age of onset around 40\% unknown causes.[24] Chromosomal aberrations are very common, as they affect $7.5 \%$ of all conceptions.[22,25]

Even though genetics plays the major role in ID, ID is not by itself one genetic disorder. Each pregnancy carries a risk of 1 in 40 that the child will have birth defect. Congenital malformations and genetic disorders occur in approximately 1 in 20 live births. [7] Chromosomal anomalies associated with ID account for up to $40 \%$ of severe cases and $10 \%-20 \%$ of mild cases. Subtelomeric aberrations may explain up to $5 \%$ $10 \%$ of previously unknown cases.[25,19] Fragile $\mathrm{X}$ syndrome is the second most common chromosomal cause of ID after
Down syndrome.[3] It shows incomplete penetrance. Carrier testing for fragile $\mathrm{X}$ syndrome is difficult and often negative. $[2,5]$

In autosomal dominant inheritance (e.g. Tuberous sclerosis), the risk of recurrence is $50 \%$ for each pregnancy. If tuberous sclerosis is diagnosed, both parents should be examined carefully, because the mutation is inherited in about $28 \%$ of cases.[2,3]

Most metabolic disorders belong to the autosomal recessive inheritance category and the risk of healthy carrier parents having an affected child is $25 \%$ for each pregnancy.[2,3,5]

Approximately, $50 \%$ of children with Cerebral Palsy have normal intelligence despite major motor deficits, so that they cannot be labelled as ID without an individualised evaluation.[3] Klinefelter syndrome is the most common cause of hypogonadism in the male and parents are characteristically sterile ${ }^{[3]}$ and they are frequently associated with depression. [2]

When the causes are unknown, prognosis is uncertain and the planning and provision of the services is difficult and the families tend to develop wrong beliefs, unrealistic expectations and may turn to other unproved alternative approaches of treatment. ${ }^{[2,8]}$

\section{Co-morbidity}

The study of McLaren and Bryson (1987) indicated that neurological disorders are frequently associated with MR, especially if the retardation is severe.[12] Seizure disorders in $15 \%-30 \%$ of patients, cerebral palsy and other motor handicaps were found in $20 \%-30 \%$ of patients and sensory impairments in $10 \%-20 \%$ of patients.[2,5,11] For example, visual impairment and conductive hearing loss are seen in Down syndrome in more than $50 \%$ of cases, which impair their learning and functioning, and thus early diagnosis and intervention are very important.[2,5] Clinically, if a child with Down syndrome develops brisk reflexes, we have to suspect odontoid hypoplasia induced atlantoaxial dislocation. Most children with trisomies die before malignancy develops, but since Down syndrome children live long we see leukaemia in them. As for carcinogenesis one needs 2 mutations in a cell since Down syndrome already had a mutation present from foetal life and hence a second mutation can produce the malignancy.

The study on the Isle of Wight found that the prevalence of mental disorders in MR is several times higher.[26] The more recent population-based studies also found the prevalence was up to $70 \%$, significantly higher than general population. $[2,5]$ ID is frequently associated with Pervasive developmental disorders. ${ }^{[2,5]}$ About 75\% - 80\% of children who have autistic disorder also have ID. ADHD, stereotypic movement disorder, self-injurious behaviour, pica, dementia, conduct disorder, oppositional defiant disorder, schizophrenia and other psychotic disorders, aggression, mood disorders, adjustment disorders are frequently associated. $[2.5,9,12,13,27.28]$ About $2 \%$ - 3\% meet the criteria for schizophrenia, which is $2-3$ times higher than the general population.[5] Negative self-image, low self-esteem, interpersonal dependence, low frustration tolerance, rigid problem-solving style, poor impulse control, etc., are common personality factors. [5] 


\section{Life Expectancy and Mortality}

People with ID have an increased risk of morbidity and mortality compared with general population ${ }^{[2,5,9.11,29]}$ and complications are numerous.[9] Those with more severe forms had lower life expectancy compared to general population. [9] Life expectancy was similar across genders.[27] In a study of young people in one state in US, mortality was 3 times higher than average.[30] In Denmark, preventable mortality was 4 times higher than average.[31] Life span is increasing in ID, especially among people with Down syndrome. Most common cause of death is still respiratory disease, swallowing and feeding problems and gastrooesophageal reflux. Up to age 35 , mortality in Down syndrome is comparable with ID of other causes, subsequently the increase was more rapid in DS and doubled every 6.4 years compared to 9.6 years for people without DS.[29,30] Life expectancy in mild-to-moderate retardation is around 55 years and in profound retardation 43 years.[32]

Mortality studies fall into 2 classes, the first focusing on the predictors of mortality-morbidity and self-care skills are strongly associated with survival and the second focuses on longevity of various cohorts and life tables are used as tools.[2,5] In DS females, there is more mortality.[33] Presence of medical difficulties are more in severe MR in early years making them more vulnerable.[34] Persons with profound MR with multiple disabilities and inability to ambulate or selffeed have a much shorter life expectancy.[35] Death is often sudden and unexpected, especially among ID with seizure disorders.[36,37] Klinefelter syndrome (XXY) is the most common cause of hypogonadism in males and patients are characteristically sterile.[2,3,5] Most of the male Down syndrome patients are sterile. Down syndrome girls may achieve menarche. Congenital heart defects increase morbidity and mortality. Life threatening thrombotic events are common in homocystinuria due to platelet dysfunction. [3] ID by itself is not associated with increased risk of suicide.[38]

\section{Management}

The Goal of Treatment is to reduce the associated disability in ID, since Intellectual Disability is a functional disability. There are three aspects to the treatment:

1. Treatment of the underlying aetiological disorder (e.g. PKU, Galactosaemia, Hypothyroidism, Wilson's disease) if identifiable.

2. Treatment of the co-morbid conditions that add to the disability (physical [e.g. epilepsy], mental [e.g. schizophrenia]).

3. Interventions targeted at the functional disability of the mental retardation itself: educational, habilitative and supportive approaches depending upon the person's individualised needs.

Effective care, training and management of a multifaceted problem of intellectual disability requires a multidisciplinary team work with effective exchange of information, observation, interpretations and suggestions. Problems are multiple as ID is associated with double, triple and multiple deficiencies and disabilities. Identifying various abilities and specific skills and knowing the limitations help the management process. So prevention of ID is more important than the treatment of ID.
Primary prevention measures like immunisations against congenital rubella, measles encephalitis, $\mathrm{Rh}$ incompatibility; measures to prevent lead intoxication, iodine deficiency and teenage pregnancies; neural tube defect prevention by administering vitamins; better neonatal care; measures to prevent foetal alcohol syndrome, foetal hydantoin syndrome, childhood trauma, accidents; prenatal diagnosis and elective termination of pregnancy (e.g. Down syndrome); and screening parents who are carriers are important. The recurrence rate is $5 \%$, if there is a history of one child with neural tube defect. The recurrence risk calculations are based on the facts of genetic epidemiology.

Since genetic factors play the major role, genetic counselling should be provided before pregnancy particularly if the following factors are there[7]:

a. History of repeated reproductive failures.

b. Mother's age $>35$ years at the time of pregnancy.

c. Father's age $>55$ years.

d. Birth of a child with ID in the family.

1. Consanguinity.

2. Positive screening test of AFP and beta-HCG.

3. Positive USG (e.g. microcephaly, IUGR).

4. Exposure to known teratogens.

5. Having a genetic disorder and are planning a family.

6. Already having a child or relative with a genetic disorder.

7. Being a carrier of a genetic disorder, because they are members of a particular ethnic group.

Approximately, 5\% of Down syndrome is due to translocation and when a translocation is found in Down syndrome the parents should be subjected to cytogenetic study as one of them could be a balanced carrier. The recurrence risks if either parent has a $21 / 21$ translocation is $100 \%$. In contrast in the other types of Down syndrome like trisomy 21 , the empiric recurrence risk is only $1 \%-2 \%$ and there is not much increased risk for children of their distant relatives. In trisomy 21, the mothers' karyotypes are normal..[5]

Secondary prevention include early diagnosis and treatment (e.g. PKU, Galactosaemia, congenital hypothyroidism, Wilson's disease). It also includes planning or genetic counselling after birth of a child with a genetic disorder. Pedigree analysis, thorough and careful clinical examination, biochemical studies, chromosomal analysis, imaging techniques, detection of various disabilities and evaluation of various abilities and skills, etc., all play their role in individual cases.

Tertiary prevention could be called habilitation as well[39] and it aims to improve functional level. It also supports early treatment and prevention of co-morbid conditions that could reduce functioning, both medical and mental. So its aim is to help an individual to attain full developmental potential.

The current approach in the management of ID is based on the following principles: The normalisation principle ${ }^{[40]}$ which is giving support based on norms of mainstream society, the right to community living, education and training as much as possible, employment, use of normal community services and facilities, and advocacy and appropriate protective measures. 
Reiss and Benson (1985) summarised the guidelines for psychotherapy in ID, which include the following[41]:

1. Appropriate goals setting - common goals include improvement in self-image and impulse control, understanding disabilities and strengths.

2. The verbal techniques should be adapted to the patient's language and cognitive level, and the nonverbal ones should be age appropriate.

3. Limits and directions should be used as needed, as nondirective therapy might lead to a patient's confusion.

4. The therapist has to be active, supportive, but not paternalistic and has to use them as a treatment tool.

5. The therapist is involved in all treatment programmes collaborating with other health care providers and family.

Group therapy might be particularly useful for understanding disabilities and to learn social skills.[5] In behaviour therapy, rewards are used to the person's cognitive level and objectionable behaviours are replaced with appropriate behaviours.[42] A well-designed behavioural milieu can produce good improvement in disturbed behaviour.[2,5,9] It teaches appropriate skills ranging from basic skills like dressing to more sophisticated skills like socialisation, assertiveness, etc.[2,5] Cognitive behavioural therapy can be used to correct polarised thinking in borderline-to-mild ID.[2,43] Rational emotive therapy changes the perceptual set, decreases anxiety and irrationality and increases self-esteem and internal control in mild-tomoderate ID. [2] Play therapy helps the child to learn many things like give and take, socialisation, acting out, spending excessive energy in a socially acceptable way, co-ordination, etc.[43,44] Speech therapy, occupational therapy, vocational training and physiotherapy to develop communication, sensory, motor and play skills and assist education, making them self-reliant. $[2,41,42,43]$ Published results are few about the usage of Electroconvulsive Therapy, but there does not appear to be an increased vulnerability to its adverse effects. [45] Pharmacotherapy is usually symptom-oriented or towards the co-morbid psychiatric problems ${ }^{[46]}$ and controlled studies are relatively few. ${ }^{[47]}$ Drugs should not be used merely to suppress a single, objectionable behaviour without considering the quality of life and they should not be used for staff convenience or as punishment and at the expenditure of training programs.[48]

The caretaker of a mentally handicapped child needs all types of support. It is more so when the child is the only child for the family or a very 'precious' child for the parents. Severity of the retardation augments the strain exponentially and presence of behaviour problem compounds it. Moreover, the belied expectations, comparisons with other children in the vicinity, frustrations during the management and projections into the future make the problem one of the most strenuous ordeal for anyone to face.[49,50,51,52,53,54,55]

Problems in decision-making about the management of the mentally handicapped child are many and invariably need the expertise of the professional. When definitive therapies are not well established, confusion confounds the choice. All that matters to the caregiver is about 'who will give the best results in the shortest time, at minimal costs, without adverse consequences and with minimal distortion in his day-to-day life.'
The Other Systems of Management for the Mentally Retarded Child are as Follows

\section{Magico-Religious Approaches}

They include visits to various pilgrimage centres, offerings to deities, specific rituals, prayer meetings, feeding the poor and other donations, astrological advices and others. The exact modus operandi might differ from one religion to other, but the faith remains the central concept.

\section{Ayurvedic Approach}

It identifies three physiological complexes called Doshas; Vayu, Pitta and Kapha and good health presumes an ideal balance of them. After identifying what type of tridosha predominates, the imbalance is set right by drugs, diets and practices. 'Manasa Mandata' is the term used for mental retardation. ${ }^{[56]}$ Generally, patients with physical disabilities prefer such centres.

\section{Siddha Approach}

Herbs with medicinal properties, natural products including alkaloids, concoctions of barks and leaves, external applications and oxides of heavy metals constitute the therapeutic armamentarium. Based on the assumption that even the defective system can be stimulated to full and nearnormal activity, a planned long-term management is envisaged.

\section{Homeopathic Approach}

Use of minimal dosage of drugs is the hallmark of this system. It is accepted by most of the native population as 'absolutely harmless.' Building up of the natural resistance of the body is the avowed principle of the system.

\section{Unani}

This indigenous system of management belongs more to the Northern India. Elimination of the underlying cause, correcting the abnormal humours and normalisation of tissues are the goals.

\section{Naturopathy}

This indigenous system envisages total non-usage of any external agents for the management of the illnesses. Proper diet, proper exercises, proper rest and use of natural mechanisms such as sunrays, pure air, etc., are the methods advocated.

\section{Yoga and Meditation}

This system of approach is based on Patanjali's concepts and enables the practitioner to achieve an intrapsychic harmony. The principles underlying 'asanas' and 'meditation' have been therapeutically utilised to achieve improvement in psychological functioning. Though there are different schools of yoga and meditation, all of them appear to bring about similar neurophysiological changes. They are used in many psychological conditions and cognitive deficits.[57]

The difficulties faced by the relatives in the choice of the management plan and the vacillations in their approach are best revealed in a study done by the authors. ${ }^{[8]}$ The observations of the study are as follows: 1 . Considerable number of the parents have consulted other systems of management; 2. Allopathy was considered as unsafe and that other systems were harmless. Adverse effects such as drowsiness were cited as reasons for abandoning allopathy. 
Lack of expected improvement and desire to try other systems were other reasons. 3. Cost of management in various systems varied. Homeopathy caused the least degree of strain on the parents. Siddha was the costliest followed by ayurvedha. Allopathy and religious approaches occupied the lower slot.[8]

\section{Summary}

The review emphasises the importance of properly defining the condition, early identification of the global delay, trying to identify the aetiology if possible or the syndrome or the associations, the importance of epidemiology, social background and parental role in classifying and treating the deficit, various classifications for appropriate remedial placement, frequent co-morbid conditions and their importance, life expectancy and mortality, different preventive measures and various available complementary treatment approaches.

Even though various treatments are available for intellectual disability, there is only limited evidence for their effectiveness. Know what you are going to do for the child. Without long-range goals, we are likely to be overcome by short-term frustrations. Each one may need a plan tailored to his/her own needs. A highly informed coordination between the family and therapeutic team is vital. Always start with a fresh slate. An index of suspicion is important in identifying the problem early. Repeated assessments may be required as ID is a lifelong issue and after each success, and as they gain confidence and experience they move up the ladder.

Undertake all the tests to confirm the diagnosis to rule in/out treatable causes. Assess the 'plus and minus' of each child in detail. Identify the extent to which the child can be trained or educated by constant observation, psychometric tests and feedback. The skills of each child differ and the assessment should give complete details about each of this skill, as they can be strengthened further. Know in detail about the financial implications of each step at the earliest and plan accordingly. One has to be ruthless in cutting down wasteful expenditures, particularly those which are not therapeutically called for.

Maintain your own psychological equilibrium throughout. This may be easy said than done and whenever disturbed try to identify the cause, work it up and solve it at the earliest. The quote by Sir William Osler will be appropriate here, "The practice of medicine is an art not trade, a calling, not a business. A calling in which your heart will be exercised equally with your head."

Choose a management plan, which you are convinced of satisfying all the above needs and even as you persist with it, keep an open mind to change it if needed. You are the best judge for these special children as you know all about their delights as well as their traumas. Duty makes us do things well, but love makes us do the duty beautifully.

Always remember the limitations. The therapeutic plans may not cure the problems, but they may help in offering to make life much more liveable to the unknowing patient sufferers and much less cruel to the all-knowing parent sufferers.

\section{REFERENCES}

[1] Goodman R, Scott S. Child and adolescent psychiatry. $3^{\text {rd }}$ edn. Wiley-Blackwell 2012.
[2] Gelder MG, Andreason NC, Lopez-Ibor JJ, et al. New oxford textbook of psychiatry. 2nd edn. Vol 2, Oxford university press 2009:1819-92.

[3] Kaufman DM, Milstein MJ. Kaufman's clinical neurology for psychiatrists. 7 th edn. Saunders Elsevier Inc 2014.

[4] Sexson SB. Child and adolescent psychiatry. 2nd edn. Blackwell neurology and psychiatry access series 2006.

[5] King $\mathrm{BH}$, Toth KE, Hodapp RM, et al. Intellectual disability. In: Sadock BJ, Sadock VA, Ruiz P, (eds). Comprehensive textbook of psychiatry. $9^{\text {th }}$ edn. Philadelphia: Lippincott Williams \& Wilkins 2009:3444-74.

[6] Tasman A, Kay J, Jeffrey A. Liberman, psychiatry. 2nd edn. England, John Wiley \& Sons, Ltd, Chichester 2003:687- 727.

[7] Mehta L, Dave U, Parikh AP. Genetic counselling in MR, National symposium on role of genetics in MR. Indian Psychiatric Society 1998:147-56.

[8] Kanesalingavelan K, Sabhesan S, Nammalvar N, et al. Alternate approaches to intellectual disability. J Evolution Med Dent Sci 2016;5(75):5539-41.

[9] Scheiber SC. The psychiatric interview, psychiatric history, and mental status examination, in the American psychiatric publishing textbook of clinical psychiatry. $4^{\text {th }}$ edn. Hales RE, Yudofsky SC. Washington, DC 2003:155-87.

[10] Desk reference to the diagnostic criteria from DSM-5. American psychiatric association, CBS publishers and distributors Pvt Ltd 2013.

[11] Campbell RI. Cambell's psychiatric dictionary. $8^{\text {th }}$ edn. Oxford university press 2004;18(6):10-11.

[12] Harris JC. Psychiatric disorders in persons with mental retardation, gabbard's treatment of psychiatric disorders. $4^{\text {th }}$ edn. American psychiatric publishing, Inc 2007:93-118.

[13] McLaren J, Bryson SE. Review of recent epidemiological studies of mental retardation: prevalence, associated disorders, and aetiology. Am J of MR 1987;92(3):243-54.

[14] Connor JM, Smith FMA. Population screening in essential medical genetics. $4^{\text {th }}$ edn. Oxford, Blackwell Scientific Publications 1993:113-26.

[15] Zigler E. Developmental versus difference theories of mental retardation and the problem of motivation. Am J of Me De 1969;73(4):536-56.

[16] Leonard H, Peeterson P, Bower C, et al. Prevention of intellectual disability in Western Australia. Paediatric and perinatal epidemiology 2003;17:58-67.

[17] Centers for Disease Control and Prevention (CDC). State-specific rates of mental retardation-United States, 1993. Morb Mortal Weekly Report 1996;45(3):61-5.

[18] Gissler M, Jarvelin MR, Louhiala P, et al. Boys have more health problems in childhood than girls: followup of the 1987 finnish birth cohort. Acta Paediatrica 1999;88(3):310-4.

[19] Hanji MB, Reddy VM. Meta analytical approach to estimation of pattern of mental retardation in India. Indian Journal of Psychological Medicine 2005;27(1). 
[20] Bhartiya D, Modi D, Gangal S, et al. FISH as an investigative tool in MR, National symposium on role of genetics in MR. Indian Psychiatric Society 1998:115-22.

[21] World Health Organization. Health behaviour research. New Delhi: WHO 1987.

[22] Clarke AM, Clarke DB, Berg JM. Mental deficiency: the changing outlook. $4^{\text {th }}$ edn. New York, Free Press 1985.

[23] Jones KL. Smith's recognizable patterns of human malformations. $5^{\text {th }}$ edn. Philadelphia, Penn WB Saunders 1997.

[24] Kaufmann WE, Moser HW. Dendritic anomalies in disorders associated with mental retardation. Cereb Cortex 2000;10(10):981-91.

[25] Kumara CK, Sujatha M, Usharani P, et al. Aetiology of mental retardation. In: Mental retardation in India. Usharani P, Reddy PP, (eds). Hydrabad, Osmania University 1990.

[26] Smith M, Arfin SM, Lott IT. Mental retardation and developmental delay. Genetic and epigenetic factors. Oxford University Press, New York 2006.

[27] Rutter M, Graham P, Yule W. A neuropsychiatric study in childhood, in clinics in developmental medicine. Heinemann medical books, London 1971;35/36:4379.

[28] Zigman WB, Shupf N, Serson E, et al. Prevalence of dementia in adults with and without down syndrome. American J of Ment Retardation 1996;100(4):403-12.

[29] Jackson M. Mental retardation. Freeman H (edr). A century of psychiatry. New Delhi: Mosby 2002:237-40.

[30] Carter G, Jancar J. Mortality in the mentally handicapped: a 50 year survey at the stoke park group of hospitals (1930-1980). Journal of Mental Deficiency Research 1983;27(2):143-56.

[31] Decoufle P, Andrew A. Increased mortality in children and adolescents with developmental disabilities. Paediatric and perinatal Epidemiology 2002;16(4):375-82.

[32] Molsa PK. Survival in mental retardation. JARID 1994;7(4):338-45.

[33] Strauss D, Eyman RK. Mortality of people with mental retardation in California with and without down syndrome, 1986-91. American Journal on Mental Retardation 1996;100(6):643-53.

[34] Thase ME. Longevity and mortality in down's syndrome. Journal of Mental Deficiency Research 1982;26(3):177-92.

[35] Brook CE, Eyman RK, Guter HM. Utilization of acute medical facilities in a hospital for mentally retarded. Journal of Chronic Diseases 1965;18(10):1039-49.

[36] Chaney RH, Eyman RK. Patterns in mortality over 60 years among persons with mental retardation in a residential facility. Ment Ret 2000;38(3):289-93.

[37] McKee JR, Bodfish JW. Sudden unexpected death in epilepsy in adults with mental retardation. Am J of Ment Ret 2000;105(4):229-35.

[38] Harris EC, Barraclough B. Suicide as an outcome for mental disorders. A meta-analysis. $\mathrm{Br} \mathrm{J}$ of Psy 1997;170:205-28.

[39] Eyman RK, Grossman HJ, Chaney RH, et al. The life expectancy of profoundly handicapped people with mental retardation. $\mathrm{N}$ Eng $\mathrm{J}$ of Medicine 1990;323(9):584-9.
[40] Rowitz L. The American mental retardation service system. Journal of Mental Deficiency Research 1987;31(4):337-47.

[41] Nirje B. A Scandinavian visitor. In: Changing patterns of residential services. Wolfensherger W, Kuger R, (eds). President's committee on mental retardation, Washington DC 1969:51-8.

[42] Reiss S, Benson BA. Psychosocial correlates of depression in mentally retarded adults: in. Minimal social support and stigmatization. Am J Mental Deficiency 1985;89(4):331-7.

[43] Sadock BJ, Sadock VA. Kaplan and Sadock's synopsis of psychiatry. $10^{\text {th }}$ edn. By Lippincott Williams \& Wilkins USA 2007.

[44] De Sousa A, De Sousa D, De Sousa A. Child psychiatry. 1st edn. Mumbai, National Book Depot 2004:53-62.

[45] Thuppal M, Fink M. Electro convulsive therapy and mental retardation. J ECT 1999;15(2):140-9.

[46] Matson JL, Bamburg JW, Mayville EA, et al. Psychopharmacology and mental retardation: a 10 year review (1990-1999). Res Dev Disabil 2000;21(4):263-96.

[47] Antonacci DJ, de Groot CM. Clozapine treatment in a population of adults with mental retardation. J of Clinical Psy 2000;61(1):22-5.

[48] Rinck C. Epidemiology and psychoactive medication. In: Reiss S, Aman MG (eds). The international consensus handbook. Ohio State Univ Nisanger Center, USA, 1998:31-44.

[49] Gandotra VS. Management problems and practices of home-makers with a disabled member in the family. Indian Journal of Social Work 1984;45(4):485-90.

[50] Sen A, Tuli K. Agonies of the family having a mentally handicapped child. In: Unit for family studies (eds). Research on families with problems in India. Vol. II. Bombay: Tata institute of social sciences 1991:299312.

[51] Rastogi CK. Attitude of parents towards their mentally retarded children. Indian Journal of Psychiatry 1981;23(3):206-9.

[52] Chaturvedi SK, Malhotra S. A follow-up study of mental retardation focusing on parental attitudes. Indian Journal of Psychiatry 1984;26(4):370-6.

[53] Kashyap L. Research on families with disabled individuals: review and implications. In: Unit for family studies. Research on families with problems in India. Vol. II. Bombay: Tata institute of social sciences 1991:269-89.

[54] Mak FL. Traditional medicine and cultural factors in Asia. In: Freeman H (edr). A century of psychiatry. New Delhi: Mosby 2002:211-13.

[55] Isaac MK. Role of paraprofessionals and nonprofessionals in mental health care in India. In: Murthy SR, Burns BJ (eds). Proceedings of the Indo-US symposium on community mental health. Bangalore: NIMHANS 1992:171-90.

[56] Rao AMVR, Srinivasan K, Rao KT. The effect of mandookaparni (centella asiatica) on the general mental ability (medhya) of mentally retarded children. J Res Indian Med 1973;8:9-16.

[57] Gangadhar BN, Porandla K. Yoga and mental health services. Indian J of Psychiatry 2015;57(4):338-40. 